\title{
Pulmonary Consolidation
}

National Cancer Institute

\section{Source}

National Cancer Institute. Pulmonary Consolidation. NCI Thesaurus. Code C124059.

A chest X-ray finding indicating the presence of a radio-opaque area in the lung. The opacification is caused by fluid or solid material within the airways or lung parenchyma. 